\title{
AS MÚLTIPLAS VOZES EM INSUBMISSAS LÁGRIMAS DE MULHERES, DE CONCEIÇÃO EVARISTO
}

\author{
THE MULTIPLE VOICES IN CONCEIÇÃO EVARISTO'S \\ INSUBMISSAS LÁGRIMAS DE MULHERES
}

Cesar Augusto de Oliveira Casella*

Resumo: Este trabalho tem dois objetivos interligados: discutir a visibilidade das obras de Conceição Evaristo, tendo em vista o campo literário como um espaço de poder, assim como definido por Bourdieu (1996), e construir uma abordagem discursiva de Insubmissas Lágrimas de Mulheres, com base nas noções de plurilinguismo e hibridização, tratadas por Bakhtin (2010). Assim, apresentam-se as análises de quatro personagens, de quatro diferentes contos do livro, tomando-as como exemplos da multiplicidade de vozes sociais, de discursos que circulam na sociedade e que podem ser encontradas na obra de Conceição Evaristo. Deste trabalho de análise resulta a reflexão de que a abordagem discursiva permite mostrar a importância da entrada da autora nas disputas inerentes ao campo literário.

Palavras-chave: Insubmissas Lágrimas de Mulheres; abordagem discursiva; campo literário.

Aвstract: This work has two interlinked objectives: to discuss the visibility of Conceição Evaristo's works, considering the literary field as a space of power, as defined by Bourdieu (1996), and build a discursive approach of Insubmissas Lágrimas de Mulheres, based on the notions of plurilingualism and hybridization, treated by Bakhtin (2010). Thus, the analyzes of four characters from four different tales of the book are presented, taking them as examples of the multiplicity of social voices, of discourses that circulate in society and that can be found in the Conceição Evaristo's book. From this work of analysis results the reflection that the discursive approach allows showing the importance of the author's entry in the disputes inherent to the literary field.

KEYwords: Insubmissas Lágrimas de Mulheres; discursive approach; literary field.

\footnotetext{
"Doutorando em Estudos de Literatura, na especialidade Literatura Brasileira, na Universidade do Estado do Rio de Janeiro (PPGL/UERJ). Mestre em Linguística Aplicada pela Universidade Estadual de Campinas (IEL/Unicamp). Professor de Língua Portuguesa na Universidade Estadual de Goiás (UEG/Campus Cora Coralina). E-mail: cesar.casella@ueg.br.
} 


\section{A visibilidade NO CAMPO LITERÁRIO}

A questão da visibilidade no campo literário serve de introdução para este trabalho e ajuda na compreensão da argumentação final deste texto, o qual busca uma análise que vá além do domínio das relações entre a obra e o contexto social mais imediato (a situação de interpretação, lato senso) e alcance o domínio das relações da obra com o contexto social mais amplo (o momento histórico de recepção, grosso modo).

Assim, esta análise de Insubmissas Lágrimas de Mulheres (EVARISTO, 2016) parte de um problema ressaltado por Volóchinov (2017 [1929], p. 219-220, grifo no original):

Todo enunciado, por mais significativo e acabado que seja, é apenas um momento da comunicação discursiva ininterrupta (cotidiana, literária, científica, política). No entanto, essa comunicação discursiva ininterrupta é, por sua vez, apenas um momento da constituição ininterrupta e multilateral de uma dada coletividade social. Disso surge um problema importante: o estudo do elo entre a interação concreta e a situação extraverbal mais próxima e, por meio desta, a situação mais ampla.

Em outras palavras: uma obra literária, tomada como um enunciado, é um momento no imenso universo dos discursos concretamente proferidos, o qual é, por seu turno, somente um momento da complexa e constante construção de uma dada sociedade. É importante, pois, passar do estudo da obra literária no domínio das relações da interação concreta com a situação extraverbal mais próxima para o domínio das relações com a situação sócio-histórica mais ampla.

É neste segundo domínio que se pode pensar o campo literário, conforme o estipulou Pierre Bourdieu (1996), entendido como um espaço de poder que se apresenta como uma estrutura que busca a sua própria manutenção, por meio de regras arbitrárias e de valores construídos, "um campo de forças a agir sobre todos aqueles que entram nele, e de maneira diferencial segundo a posição que ai ocupam” (BOURDIEU, 1996, p. 262).

A constituição do cânone, neste sentido, se dá dentro do campo literário e é um processo que, concomitantemente, elege e valoriza algumas obras literárias e estrutura o próprio campo, já que organiza a relação simbólica entre os leitores e os textos literários. Cabe lembrar que a legitimação do cânone literário é um processo complexo, que envolve várias instituições socialmente autorizadas para tanto (as associações literárias, a academia, o ensino escolar, os concursos literários etc.).

Cumpre notar que este processo é excludente e não está centrado nas <qualidades> intrínsecas das obras - pois estas são um efeito discursivo e não uma < propriedade natural> dos textos - e espelha uma realidade também excludente. Como escreve Regina Dalcastagnè (2019, p. 52), tratando do caso brasileiro: 
[...] nossa literatura repercute uma 'realidade' que exclui um mundo de experiências, paisagens, linguagens, problemas e, também, de possibilidades estéticas. É necessário frisar que o que está em jogo não é a capacidade de construir narrativas e de representar o mundo, mas de fazer com que o produto deste esforço seja reconhecido como literatura.

Frequentemente, argumenta-se sobre a pouca visibilidade das obras de Conceição Evaristo, ainda que se lembre também de sua importância social e de sua repercussão acadêmica (VALENTE; CARNEIRO, 2017; DALCASTAGNÈ, 2019), o que pode exemplificar a complexidade e a diferencialidade da/na constituição do cânone: pouca visibilidade midiática, mas boa aceitação na esfera crítica das universidades.

Costuma-se marcar a entrada de Conceição Evaristo no campo literário juntamente à emergência da noção de Literatura Afro-brasileira (VALENTE; CARNEIRO, 2017; DALCASTAGNÈ, 2019), ao que se pode agregar uma especificidade maior na marcação: literatura Afro-brasileira produzida por mulheres. É frequente, ainda, lembrar e listar as premiações da autora:

As condecorações ao seu trabalho são muitas. Conceição Evaristo foi tema da Ocupação Itaú Cultural, em 2017. Ganhou o prêmio Jabuti de Literatura de 2015, na categoria Contos e Crônicas, por Olhos D’Água. Recebeu, também, os prêmios Faz a Diferença - Categoria Prosa, de 2017; Prêmio Cláudia - Categoria Cultura, de 2017; e o prêmio de Literatura do Governo do Estado de Minas Gerais, de 2017. Este ano ganhou o prêmio Bravo (revista) como Destaque 2017 (DORALI, 2018).

Estas são algumas das estratégias para visibilizar a obra de Conceição Evaristo, e elas, em conjunto, mostram como se dá o jogo - no sentido de disputa - de instauração de uma obra no campo literário, pensando-se nas reflexões de Pierre Bourdieu (1996).

Assim, compreende-se que Conceição Evaristo entra no campo literário conjuntamente à edificação da noção de Literatura Afro-Brasileira, entendida como uma marcação distinta e distintiva, o que é necessário, segundo Bourdieu (1996), para que o recém-chegado conquiste seu lugar, rompendo com os pensamentos vigentes e afirmando a sua identidade, buscando ser reconhecido em sua diferença e existência.

Esboçado este contexto de inserção de Insubmissas Lágrimas de Mulheres (EVARISTO, 2016) no campo literário, com a marcação distintiva da Literatura Afro-Brasileira de feitura feminina, à guisa de introdução, passa-se aos itens que explicitam a abordagem bakhtiniana adotada neste trabalho, a qual busca estudar esta obra de Conceição Evaristo no elo entre os domínios aludidos anteriormente. 


\section{Abordagem BAKHTINIANA DA LITERATURA}

Ao explicitar o embasamento teórico de sua análise nos Problemas na obra de Dostoiévski, Mikhail Bakhtin (2003 [1929], pp. 195-196) registra a sua:

[...] convicção de que toda obra literária é interna, imanentemente sociológica. Nela se cruzam forças sociais vivas, avaliações sociais vivas penetram cada elemento de sua forma. Por isso a análise puramente formal deve tomar cada elemento da estrutura artística como ponto de vista da refração de forças sociais vivas, como um cristal artificial cujas facetas foram construídas e lapidadas a fim de refratar determinados raios de avaliações sociais, e refratá-los sob um determinado ângulo.

No que há um ponto vital do pensamento bakhtiniano: na obra literária, cruzam-se as forças vivas da sociedade e, em cada ponto formal da obra literária, encontram-se as avaliações ideológicas presentes na sociedade. A obra literária, por força de sua construção e lapidação, por refração, traz à tona os posicionamentos ideológicos existentes na sociedade.

Isto é o que se buscaria em uma análise bakhtiniana de um livro de literatura. No mesmo texto, que prefacia e apresenta a edição original de Problemas na obra de Dostoiévski, Mikhail Bakhtin explica as funções do enredo nas obras do autor. Assim, Bakhtin escreve que “o enredo em Dostoiévski é desprovido de quaisquer funções concludentes" (2003 [1929], p. 196), do que se depreende que o enredo não é monológico, fechado, mas sim dialógico, aberto.

Na continuação, ele escreve que a finalidade do enredo em Dostoiévski é a de:

[...] colocar o homem em diferentes situações que o revelem e provoquem, juntar personagens e levá-las a chocar-se entre si, mas de tal forma que não permaneçam no âmbito desse contato no interior do enredo e ultrapassem seus limites (BAKHTIN, 2003 [1929], p. 196).

Nestes entrechoques aparecem não uma construção genial do enredo ou uma elaboração primorosa da narrativa, mas, sim, as contradições e as tensões da sociedade em que a obra está imersa.

Estas poucas considerações já permitem que se pense em que medida o enredo em Insubmissas Lágrimas de Mulheres é desprovido de uma função concludente, avaliar se ele é fechado, monológico ou, ao contrário, se é aberto, dialógico. Elas permitem, também, que se reflita sobre as características das personagens de Conceição Evaristo, levando a reflexão às perguntas: As situações das personagens as fazem se revelar? Elas se chocam entre si ideologicamente? Elas ultrapassam os limites do enredo? 


\section{A personagem QUe fala Na literatura}

Silviano Santiago, em Uma Literatura nos Trópicos, postula um lugar para o discurso literário latino-americano. Um lugar que é um entre-lugar, uma posição permeável, em trânsito - ou, glauberianamente falando, em transe... - no qual "o elemento híbrido reina" (SANTIAGO, 2019, p. 17). Desta maneira, é que:

A maior contribuição da América Latina para a cultura ocidental vem da destruição sistemática dos conceitos de unidade e pureza: estes dois conceitos perdem o contorno exato do seu significado, perdem seu peso esmagador, seu sinal de superioridade cultural, a medida em que o trabalho de contaminação dos latino-americanos se afirma, se mostra mais e mais eficaz (SANTIAGO, 2019, p. 17).

A destruição sistemática dos conceitos de unidade e pureza, o trabalho de apagamento dos contornos exatos destes dois conceitos, a literatura que se faz no entremeio, pode ser vista na perspectiva daquilo que Bakhtin chamou de hibridização, definida como "a mistura de duas linguagens sociais no interior de um único enunciado", isto é, o reencontro - nada harmonioso, sempre tenso - "na arena deste enunciado de duas consciências linguísticas, separadas por uma época, por uma diferença social (ou por ambas) das línguas" (BAKHTIN, 2010 [1965], p. 156).

Para Bakhtin, o amálgama de duas linguagens (temporal e/ou socialmente diferentes), que ocorre frequente e involuntariamente no uso comum da língua, é, no romance - e, lato senso, em toda prosa narrativa ficcional - um processo literário proposital, um sistema de procedimentos artísticos que "trata-se não apenas (e não tanto) da mistura de formas e de indícios de duas linguagens e dois estilos, mas principalmente do choque no interior destas formas, dos pontos de vista sobre o mundo" (BAKHTIN, 2010 [1965], p. 158).

Assim, o que é usual e involuntário na utilização cotidiana da língua (para ficar em um exemplo banal: a forma repreensiva <não faça isto! > usada por um filho mais velho para lidar com o irmão mais novo, com a mesma entoação que ouviu da mãe, misturando em um enunciado a sua consciência linguística e a dela, separadas temporalmente) torna-se um mecanismo de representação do choque ideológico existente no interior da forma hibridizada (ainda no terreno do exemplo banal: com este enunciado < não faça isto! $>$ do irmão mais velho que reverbera a autoridade da mãe, o escritor exploraria literariamente o jugo deste sobre $o$ irmão mais novo).

A hibridização, no pensamento bakhtiniano, liga-se ao plurilinguismo social, que é definido como "a consciência da diversidade das linguagens do mundo e da sociedade que orquestram o tema do romance" (BAKHTIN, 2010 [1965], p. 134). Entra em cena a variação (os jargões, as gírias, os sotaques, os idioletos etc.) de uso das línguas. O mundo é heterogêneo 
- linguisticamente, mas também ideologicamente e, por consequência, discursivamente - e a literatura tem de se apresentar também heterogênea - composicional, temática e estilisticamente - para que ela se torne plena, viva, importante.

O escritor, ainda que Bakhtin trate mais especificamente do romancista, não percebe a língua - e a linguagem - como algo unificado, puro, convencionalmente incontestável e peremptório. A língua - e a linguagem - é dada ao escritor pelos diferentes estratos sociais existentes e, assim, apresenta-se em constante e múltipla variação. O plurilinguismo social, então, "penetra no romance, por assim dizer, em pessoa, e se materializa nele nas figuras das pessoas que falam" (BAKHTIN, 2010 [1965], p. 134).

O plurilinguismo penetra no romance tanto quanto penetra em um livro de contos como Insubmissas Lágrimas de Mulheres, que em alguma medida pode ser lido como um romance, como uma obra unificada composicionalmente por uma voz narrativa que organiza e que enseja as entrevistas, os diálogos em que se contrapõem as muitas vozes sociais.

No postulado bakhtiniano, para dar vazão ao plurilinguismo social que penetra e rege o romance, são necessários os homens/heróis/personagens que falam, pois estes, falando e agindo na literatura trazem os discursos originais, heterogêneos, plurilíngues e híbridos que se encontram na sociedade.

Bakhtin especifica que o entendimento deste personagem que fala e de sua palavra vem da compreensão de três momentos: 1. os sujeitos e as palavras são objetos de representação verbal e literária; 2. o sujeito que fala no romance é social e histórico e sua linguagem é social e histórica e nunca um dialeto individual; 3. o sujeito que fala no romance é um ideólogo e suas palavras são ideologemas (BAKHTIN, 2010 [1965], p. 135).

Para o escopo deste trabalho, interessa mais especificamente o postulado bakhtiniano de que o personagem que fala e age na literatura é sempre iluminado ideologicamente. Assim:

O sujeito que fala no romance é sempre, em certo grau, um ideólogo e suas palavras são sempre um ideologema. Uma linguagem particular no romance representa sempre um ponto de vista particular sobre o mundo, que aspira a uma significação social (BAKHTIN, 2010 [1965], p. 135).

O personagem que fala na literatura, com o trabalho artístico do escritor que traz a hibridização e o plurilinguismo social, representa um ponto de vista particular sobre o mundo, isto é, representa linguisticamente uma ideologia, ou melhor, dentro da abordagem escolhida para este trabalho: o personagem que fala em um texto literário representa um discurso.

Para apresentar sucintamente a noção de discurso, como ela é compreendida pela Análise do Discurso, traz-se para este estudo a explicação que Cleudemar Fernandes constrói sobre o conceito: 
[O discurso] não é a língua, nem texto, nem a fala, mas necessita de elementos linguísticos para ter uma existência material. Com isso, dizemos que discurso implica uma exterioridade à língua, encontra-se no social e envolve questões de natureza não estritamente linguística. Referimo-nos a aspectos sociais e ideológicos impregnados nas palavras quando elas são pronunciadas (FERNANDES, 2008, p. 13).

Uma abordagem discursiva busca, portanto, analisar os aspectos ideológicos - sociais e históricos - que estão impregnados nas palavras quando elas são enunciadas. A análise, neste sentido, busca na materialidade da língua os aspectos ideológicos que estão presentes, voluntária ou involuntariamente. O próximo item busca apresentar uma análise deste tipo.

\section{AS MÚLTIPLAS VOZES EM INSUBMISSAS LÁGRIMAS DE MULHERES}

Em Insubmissas Lágrimas de Mulheres há 13 contos e a presença da escrevivência, fusão da escrita com a vivência, uma marca criativa de Conceição Evaristo. No todo, há uma peculiar hibridização da voz das protagonistas (o trabalho ficcional foi feito sobre entrevistas reais com mulheres negras de diferentes idades), da voz da narradora que dialoga com as personagens que contam suas histórias e da voz da própria autora. Desta hibridização primordial, surgem as < vozes-mulheres $>$, que buscam explicitar as suas dores, mostrar os seus anseios e temores, ao mesmo tempo em que buscam revelar a capacidade de resistir e de enfrentar o sofrimento.

Como escreve Adélcio Cruz (2012, p. 257):

[...] as tramas expostas pelos tecidos narrados interconectam-se: seja pela repetição da intromissão física e/ou simbólica da violência no seio familiar, seguida de reação e narrativa, seja pela condição negra e feminina urbano-contemporânea.

Esse procedimento amarra um conto ao outro, dando um caráter unificado ao conjunto, mesmo que as personagens/protagonistas sejam diferentes entre si e suas narrativas sejam tematicamente diversas. Por isso, acima se consignou que Insubmissas Lágrimas de Mulheres pode ser lido quase como um romance.

Cada conto recebeu por título o nome de uma mulher, protagonista da narrativa, fato que também é sintomático do agrupamento de vozes narrativas aludido anteriormente. Assim, na análise, trata-se de identificar e discutir, na personagem que fala no conto, um discursodentro da heterogeneidade discursiva... - que se apresenta na sociedade. Isto significa que, no mosaico de personagens de Insubmissas Lágrimas de Mulheres, pode-se ver o mosaico de discursos - de linguagens e de ideologias - presente na sociedade brasileira atual.

Estes primeiros pontos já permitem responder às questões sobre o enredo apresentadas inicialmente. O enredo - haveria que se dizer, talvez, os enredos... - em Insubmissas Lágrimas de 
Mulheres é dialógico, no sentido de que não é concludente, não é fechado. Conceição Evaristo não apresenta e impõe a sua visão de mundo, mas faz com que ela ressalte e se refrate no entrechoque das posições ideológicas das personagens.

Isto passa, necessariamente, pela escolha formal de narrativas que se dão a partir de entrevistas. Cria-se um jogo de vozes, entre a narradora e as protagonistas, todas mulheres, que permite e induz a refração da voz da autora. Interessa notar, ainda, que as histórias das personagens/protagonistas são oferecidas em um diálogo, na forma de entrevista, o que faz com que haja a transmissão do discurso de outrem - um tema caro à Volóchinov, que, como se sabe, o apresentou e o desenvolveu em Marxismo e Filosofia da Linguagem (2017 [1929]).

$\mathrm{Na}$ transmissão do discurso de outrem, os choques são inevitáveis. Nesta transmissão entram em cena toda uma cadeia de interpretações, incompreensões, complementações etc., que agem como filtros, como molduras, que desestabilizam a imagem ingênua da comunicação verbal como harmoniosa. Nestes choques, nos desentendimentos e entendimentos decorrentes da interação verbal entre as personagens/protagonistas e a narradora, é que se compreende a integralidade das personagens em suas posições ideológicas. Isto faz com que as personagens de Insubmissas Lágrimas de Mulheres não estejam chapadas ao enredo e ganhem uma dimensão social e cultural.

Um exemplo ilustrativo: Em Mary Benedita, de início, a narradora não compreende a chegada da protagonista. Imagina que a moça tivesse ido lhe procurar para "pedir alguma informação sobre a vida na capital", ou "pedir trabalho", "ou ainda para solicitar algum auxílio" (EVARISTO, 2016, p. 69). Ao entender que Mary Benedita quer lhe "oferecer o seu corpo/ história" (EVARISTO, 2016, p. 69) a narradora supera o cansaço da sua viagem de vinda e põe-se na escuta. Neste desencontro inicial, neste entrechoque de expectativas e suposições, funda-se, discursivamente, a profundidade da representação da personagem/protagonista.

Agora, afinal, é possível passar para a identificação e análise dos discursos presentes nos contos. Em Isaltina Campo Belo, a voz da narradora traz à superfície linguística, entre outras, as questões de gênero, de sexualidade e da violência contra a mulher, as quais não estão presentes somente neste conto.

Emoldurada pela voz da narradora, que nos descreve a protagonista com "idade indefinida", "cabelos curtos, à moda black power" e marcados por "chumaços brancos", "rosto negro, sem qualquer vestígio de rugas" (EVARISTO, 2016, p. 55-56), mas com uma filha de 35 anos, chamada Walquíria, cuja foto não sai da mão da mãe durante a entrevista, Isaltina narra que:

Minha mãe, meu pai, a operação de apendicite, a menstruação de minha irmã a escorrer pela perna abaixo, a minha logo depois, nós duas ouvindo várias vezes os ensinamentos de como deviam se comportar as mocinhas e meu irmão subindo em árvores com o consentimento de minha mãe... Nesse emaranhado de lembranças, lá estava meu 
corpo-mulher, a cena do estupro, minha filha nascendo. E, de repente, uma constatação que me apaziguou. Não havia um menino em mim, não havia nenhum homem dentro de mim. Eu, até então, encarava o estupro como um castigo merecido, por não me sentir seduzida por homens. Naquele momento, sob o olhar daquela moça, me dei permissão pela primeira vez. Sim, eu podia me encantar por alguém e esse alguém podia ser uma mulher (EVARISTO, 2016, p. 66).

Ao falar, a personagem/protagonista Isaltina Campo Belo traz, em termos bakhtinianos, palavras que são ideologemas, índices de sua ideologia, de sua visão de mundo, os quais aspiram uma significação social. Isaltina, assim, traz um feixe discursivo em que se encontra o discurso anti-homofobia, o discurso da liberação sexual e o do combate à violência contra a mulher. Um feixe discursivo poderoso e representativo de questões atualíssimas na sociedade brasileira.

Ao falar, a protagonista traz, ainda, a hibridização categorizada por Bakhtin (2010 [1965]). Quando ela diz que "encarava o estupro como um castigo merecido" há um enunciado com duas consciências linguísticas, um enunciado que traz duas vozes: a de Isaltina e a voz social do conjunto de mulheres que já se expressaram desta maneira. No entanto, estas consciências estão separadas: Isaltina sabe, no momento em que narra a sua história, que a expressão linguística <castigo merecido> é derivada de uma sociedade estruturalmente machista e a sua fala ilumina ideologicamente a questão.

Em Rose Dusreis, a voz da personagem/protagonista traz à superfície linguística a denúncia do racismo, o que, diga-se, não é exclusividade deste conto. A narradora descreve Rose como "uma mulher de porte pequeno a aparentar uma extrema fragilidade" (EVARISTO, 2016, p. 105) que, entretanto, é uma dançarina vigorosa, uma bailarina e "professora de balé clássico, de dança moderna, de balé afro, de jazz, de sapateado e de dança de salão" (EVARISTO, 2016, p. 106), além de ser dona da academia mais procurada da cidade. Rose conta um episódio de sua vida escolar, no qual, em uma festa de fim de ano, ela iria "encarnar o papel de uma bonequinha preta que cantava e dançava" (EVARISTO, 2016, p. 107), um papel desejado pela personagem/protagonista.

Assim, Rose narra:

Confiantemente eu dava os primeiros passos de exibição para uma plateia. Um dia, a própria professora Atília Bessa veio assistir aos ensaios, que estavam sob o encargo de outra professora, e elogiou o meu desempenho, dizendo que eu tinha muito jeito para dança. Esperançosa, aguardei que ela me convidasse para ser sua aluna no balé. Aguardei não só o convite dela, mas a oportunidade de ser a bonequinha negra. $E$ ainda esperei, também, alguma explicação sobre as razões da troca por outra menina. Aguardei o porquê da minha substituição, já na semana 
da festa, quando uma menina branca, pintada de preto, no meu lugar, fingiu ser a bonequinha negra que eu era (EVARISTO 2016, p. 110).

Ao falar, a personagem/protagonista Rose Dusreis traz à tona o discurso racista, onipresente na sociedade brasileira. O enunciado <menina branca pintada de negro $>$, referente à menina que a substitui na apresentação escolar, é o índice maior do preconceito racial exposto no conto, é a iluminação ideológica que advém da fala da personagem/protagonista. É na usurpação da identidade de Rose que aparece a hibridização bakhtiniana, a presença de duas vozes, duas consciências separadas pela distância social: uma, a da protagonista, vítima do racismo, outra, a voz social do racismo estrutural brasileiro.

Em Shirley Paixão a voz da personagem/protagonista traz o discurso da sororidade, compreendida como uma irmandade entre mulheres (pensando-se que, em latim, soror significa irmã), na qual é importante a união e empatia entre as mulheres. Uma questão atual, portanto. Isto é o que a fala de Shirley ilumina ideologicamente, ao contar que:

Quando ele veio para casa, trouxe as três meninas. Elas eram ainda pequenas, as minhas duas regulavam idade com as dele. As cinco meninas tinham idades entre cinco e nove anos. E, logo-logo, selaram irmandade entre elas. Pessoas desconhecidas, não sabedoras de nossa vida, nem imaginavam que o parentesco entre elas não tivesse o laço sanguíneo, pois fisicamente se assemelhavam. (...) Eu, feliz, assistindo às minhas cinco meninas crescendo. Uma confraria de mulheres. Às vezes, o homem da casa nos acusava, implicando com o nosso estar sempre junto. Nunca me importei com as investidas dele contra a feminina aliança que nos fortalecia. Não sei explicar, mas, em alguns momentos, eu chegava a pensar que estávamos nos fortalecendo para um dia enfrentarmos uma luta. Uma batalha nos esperava e, no centro do combate, o inimigo seria ele (EVARISTO 2016, p. 27-28).

Em Adelha Santana Limoeiro, a voz da narradora traz o discurso do sincretismo religioso. A entrevistadora, afetada pela sensação de que já havia se encontrado com a personagem/ protagonista antes, algo impossível dentro da estrutura ficcional do conto, trata de encaixar a imagem dela numa estampa religiosa de sua memória. Isto permite ver os choques e a cadeia de interpretações, incompreensões, complementações etc., próprios da transmissão do discurso de outrem, aludidos anteriormente neste trabalho. A imagem de Adelha, emoldurada pela voz da narradora, é construída como a de uma santa negra:

E como as ilustrações de santas e de santos, na grande maioria, são brancas, para confirmar os meus achados de parecença, resolvi crer que Adelha Santana Limoeiro parecia com Santana (era assim que falávamos quando criança), quando a santa fosse negra. Buscando assegurar ainda mais a validade de meu invento de semelhança para lá e parecença para 
cá, na ideia de sincretismo, encontrei a solução. Confundi tudo. Adelha Santana Limoeiro, negra, poderia, sim, relembrar a santa branca, a Santana, pois a avó de Jesus aparece sincretizada com Nanã, mito nagô. Misturando a fé, fiz o amálgama possível (EVARISTO, 2016, p. 35-36).

Além da presença do discurso de sincretismo religioso, este trecho permite ver o plurilinguismo e a hibridização em um percurso, como marcas formais - ou melhor, linguísticas - de irrupção do discurso sincrético: Santa Ana $>$ Santana $>$ Nanã. Há o plurilinguismo social na mistura de latim, português e iorubá. Há a hibridização no uso de $<$ Nanã $>$ que traz um amálgama de culturas, portanto de consciências sociais diferentes.

\section{EM ABERTO}

Ao apresentar-se estas conclusões, não há a pretensão do esgotamento de identificação e de análise dos discursos presentes nas falas das personagens. Há, obviamente, mais a ser explorado em Insubmissas Lágrimas de Mulheres. Também não há a pretensão de um fechamento teórico - incoerente com a abordagem bakhtiniana, assinale-se de passagem - mas somente a busca por assinalar itens que permitam reabrir - dialogicamente - a reflexão.

Tzvetan Todorov (2003, p. XXX) postula, no prefácio da edição francesa de Estética da Criação Verbal, que na visão de Bakhtin para literatura:

Mais do que 'construção' ou 'arquitetônica' a obra é acima de tudo heterologia, pluralidade de vozes, reminiscência e antecipação de discursos passados e futuros; cruzamento e ponto de encontros; ela perde de repente sua posição privilegiada. Portanto, Bakhtin reencontra a transtextualidade, não mais no sentido dos 'métodos' formalistas, mas no sentido de um pertencer à história da cultura.

Esta mirada bakhtiniana é que permite, então, abordar a obra de Conceição Evaristo não tanto em suas minúcias formais (a estrutura narrativa, a construção de personagens etc.) mas sim como um ponto de entrecruzamentos de vozes plurais, de diferentes discursos, como uma obra que pertence à cultura - e à sociedade - brasileira atual.

Isto faz - ou poderia fazer - com que se compreenda a importância da discussão sobre a entrada no campo literário (BORDIEU, 1996) de Conceição Evaristo, concomitantemente a emergência da noção de Literatura Afro-Brasileira. É preciso, neste campo de poder simbólico, conquistar uma posição, romper com os pensamentos vigentes e afirmar as identidades. As insubmissas lágrimas de mulheres negras mostram que é preciso não se submeter aos procedimentos naturalizados pelo poder estabelecido no campo literário, masculino e branco. 


\section{REFERÊNCIAS}

BAKHTIN, M. A respeito de Problemas da Obra de Dostoiévski. In: BAKHTIN, M. Estética da criação verbal. 4. ed. Tradução: Paulo Bezerra. São Paulo/SP: Martins Fontes, 2003.

BAKHTIN, M. A pessoa que fala no romance. In: BAKHTIN, M. Questões de literatura e de estética: a teoria do romance. 6. ed. São Paulo/SP: Hucitec, 2010.

BOURDIEU, P. As regras da arte: gênese e estrutura do campo literário. São Paulo/SP: Companhia das Letras, 1996.

CRUZ, A. S. Conceição Evaristo: Insubmissas Lágrimas de Mulheres. Estudos de Literatura Brasileira Contemporânea, Brasília/DF, n. 39, p. 255-258, jan./jun. 2012. Disponível em: https:// periodicos.unb.br/index.php/estudos/issue/view/888. Acesso em: 9 dez. 2019.

DALCASTAGNÈ, R. O que escondem os muros do universal. In: DUARTE, C. L. et al. (Org.). Mulheres em letras: diáspora, memória, resistência. Viçosa/MG: As Organizadoras, 2019.

DORALI, I. Conceição Evaristo: imortalidade além de um título. Revista Periferias, online, Rio de Janeiro/RJ, v. 2 n. 2, 2018. Disponível em: http://revistaperiferias.org/materia/conceicaoevaristo-imortalidade-alem-de-um-titulo/. Acesso em: 24 set. 2019.

EVARISTO, C. Insubmissas lágrimas de mulheres. 2. ed. Rio de Janeiro/RJ: Malê, 2016.

FERNANDES, C. A. Análise do discurso: reflexões introdutórias. 2. ed. São Carlos/SP: Editora Claraluz, 2008.

SANTIAGO, S. Uma literatura nos trópicos. Recife/PE: Cepe, 2019.

TODOROV, T. Prefácio à edição francesa. In: BAKHTIN, M. Estética da Criação Verbal. 4. ed. Tradução: Maria Ermantina de Almeida Prado Galvão. São Paulo/SP: Martins Fontes, 2003.

VALENTE, M. I.; CARNEIRO, T. D. Literatura Afro-brasileira rompendo barreiras através da tradução: algumas considerações sobre a recepção de Ponciá Vicêncio na França. Trabalhos em Linguística Aplicada, Campinas, n (56.2): 711-728, maio/ago. 2017.

VOLÓCHINOV, V. Marxismo e Filosofia da Linguagem: problemas fundamentais do método sociológico na ciência da linguagem. 1. ed. Tradução: Sheila Grillo e Ekatarina Vólkova Américo. São Paulo/SP: Editora 34, 2017.

Recebido para publicação em: 21 maio 2021. Aceito para publicação em: 20 jul. 2021. 